\title{
Pyramidal Lobe
}

National Cancer Institute

\section{Source}

National Cancer Institute. Pyramidal Lobe. NCI Thesaurus. Code C33437.

A conical thyroid gland lobe. When it is present, it usually arises from the isthmus. 